\title{
EL TRACTATUS DESENMASCARADO \\ (Réplica a Margáin)
}

LUIS VILLORO

Universidad Autónoma

Metropolitana

En el número 19 de Crítica apareció un artículo mío, "Lo indecible en el Tractatus", en el que me propuse exponer e interpretar la doctrina sobre "lo que no puede decirse", para arrojar alguna luz sobre la paradoja con que termina la obra. En el número siguiente, Hugo Margáin -quien parece haberse especializado en demoledoras notas críticas- me concede el honor de haber escrito el Tractatus. En efecto, no sólo me atribuye la paternidad de todas las tesis de esa obra que expongo o gloso en mi artículo, sino aún de la "visión del mundo" a la que conduce. Lamento tener que decepcionarlo: el autor del libro es otro.

Margáin tiene además el cuidado de poner frases en mi boca, que cita entrecomilladas, como si yo las hubiera escrito. Dice, por ejemplo: "Las imaginarias relaciones eróticas entre el místico de Villoro y el mundo son curiosas: '¡mun. do, eres arbitrario, eres indiferente, no te importa que te quiera o te odie, no puedo entender por qué existes, tu exitencia no depende de mi voluntad... ! pero no me importa cómo seas, de todas formas concuerdo contigo ...? Todo esto es claramente decible y más que mística, recuerda descripciones psicológicas de etapas primitivas del desarrollo de la personalidad" (Crítica, núm. 20, p. 115). Tengo que admitir que mi lenguaje nunca ha alcanzado un estilo tan vivaz y florido. Más bien, podría reconocerse en ese párrafo la misma seguridad y firmeza con que mi interlocutor no sólo rechaza, indignado, mis "incomprensibles o falsas tesis", sino que revela, detrás de ellas, mi "gusto oscurantista", una "invita- 
ción a la muerte" y un solapado intento de "glorificar a la mística". Hubiera podido agradecer a este nuevo cruzado de la razón que me revelara mis verdaderas inclinaciones y me pusiera en guardia contra ellas. Por desgracia, no puedo hacerlo. Porque casi todo lo que escribí, que a Margáin le parece "a veces oscuro, a veces ininteligible, a veces absurdo" (Ibid., p. 110), no lo digo yo sino Wittgenstein.

Con señalar el quidproquo podría terminar esta aclaración. Cabría sólo añadir una nota final. Si tuviera la penetración de mi interlocutor para descubrir las "etapas primitivas del desarrollo de la personalidad" a que responde su réplica, podría considerar como mala fe su maniobra de atribuir al intérprete las tesis de la obra que interpreta, con el propósito patente de confundir al lector. Pero mi agudeza no alcanza a tanto. Después de todo, si esa maniobra no es usual en la crítica filosófica seria, puede aceptarse en otros géneros: ¿no es acaso un recurso ampliamente utilizado en la mejor literatura panfletaria?

Sin embargo, la réplica de Margáin responde a otro propósito, tan ambicioso, que me obliga a detenerme. Margáin declara textualmente que no le interesa discutir mi exégesis del Tractatus. "Mi propósito -explica- es subvertir la visión del mundo, el lenguaje, el pensamiento, la ética, que se presenta en ese trabajo" (Ibid., p. 109). Ese "trabajo" es, supongo, mi artículo, pero cómo éste sólo expone y explica la visión del mundo del Tractatus, es obvio que el propósito de Margáin es mucho más alto: va dirigido contra la concepción del lenguaje, de la ética, del pensamiento, contra toda la visión del mundo de esa obra. Aquí no puedo menos de escuchar con respeto. ¿Encontraremos por fin la pluma que va a atreverse, en diez apretadas páginas, a poner a la luz el oscurantismo, la falsedad, la confusión mental de la visión del mundo y del lenguaje que propone Wittgenstein? ¡El Tractatus desenmascarado! Tamaña empresa merece nuestra atención.

Podemos resumir en seis renglones las objeciones con que 
Margáin logra destruir la obra de Wittgenstein (que él dirige, por excusable recurso retórico, contra su expositor).

1. La primera (Ibid., pp. 110 y 112) tiene, sin duda, la virtud de la verdadera originalidad filosófica: la que con. siste en repetir con palabras nuevas las sólidas razones antiguas. La distinción entre "mostrar" y "decir" —en que se basa todo el Tractatus- se puede rechazar con sólo admitir que lo que se muestra en un lenguaje puede ser dicho en otro de nivel lógico superior. Es la objeción que ya escribió Russell en su "Introducción" a la obra y que tantos otros comentadores, tan incansables como Margáin, han repetido. Yo mismo la presento, en relación con cierta clase de "sinsentidos", en mi artículo (Crítica, núm. 19, p. 25).

Wittgenstein era tozudo. En efecto, pese a conocer perfectamente esa objeción, no le prestó la menor atención. ¿Por qué? En primer lugar, porque tenía serios argumentos contra la teoría de los tipos de Russell, que supone la objeción. En. tiendo que Margáin no tenga tiempo de detenerse a examinar las ideas de Wittgenstein, para determinar quién tiene razón entre él y Russell. Su propósito es más radical y no puede pararse en minucias. Por desgracia, mientras no se discutan los argumentos de Wittgenstein contra la teoría de los tipos, la objeción de los distintos niveles de lenguaje cae en el vacío.

En segundo lugar, aún admitiendo la posibilidad de distintos niveles de lenguaje, eso no basta para eliminar la distinción entre "lo que se dice" y "lo que se muestra", la cual aplicaría Wittgenstein a la totalidad de los lenguajes usados. Para cualquier lenguaje $L_{n+1}$ que hablara de $L_{n}$, podría establecerse la diferencia entre las reglas usadas en $L_{n+1}$, indecibles en ese lenguaje (aunque pudieran decirse en $L_{n+2}$ ), y lo mencionado por él: lo mostrado por $L_{n}$. La distinción subsiste para cada sistema lingüístico sujeto a reglas y, por consiguiente, para el conjunto de los lenguajes usados, tomados como un todo.

2. Si algún concepto del Tractatus ha molestado a sus crí- 
ticos es la noción de "objeto". Pero es Margáin quien encuentra su formulación más precisa: Wittgenstein cayó en esa doctrina porque - nos dice - tenía una peculiar imagen del objeto. "El objeto se compara con una tira de papel mata. moscas y sus propiedades con las moscas que están pegadas" (Art. cit., p. 111). Con esas imágenes en la cabeza, el pobre de Wittgenstein no podía menos de caer en una metafísica aberrante.

Cierto, la noción de "objeto" del Tractatus responde a una concepción del análisis conforme a la cual el lenguaje debe resolverse, en último término, en signos elementales (los "nombres") cuya función ya no es describir sino simplemente designar; por consiguiente, debe haber en el mundo términos simples de esa designación: los objetos. Esta es una concepción probablemente falsa del lenguaje, como el mismo Wittgenstein reconoció posteriormente. Cabría, sin embargo, preguntarse si es falsa por las razones que aduce Margáin. Pues me temo que a su crítica podría ponérsele un reparo: se dirige contra una teoría que no está en el Tractatus. En efecto, no parece que el Tractatus hable de "objetos puros", separados de sus propiedades. Conocer un objeto es conocer todas sus propiedades internas, dice el aforismo 2.01231; el objeto ("cómo es algo") queda plenamente descrito al expresar éstas. Por otra parte, el objeto es siempre un elemento de una situación objetiva y no es nada aparte de ella (al igual que el "nombre" no es un signo aparte de la oración). Si los hechos fueran un enjambre de moscas, estos animalitos, o sus partes físicas, podrían fungir como objetos, y no un metafísico papel escondido detrás de ellos. Los objetos no tienen existencia trascendente a los hechos, como parece creer Margáin. Que su existencia sólo pueda ser mostrada, no dicha, en el uso de los nombres lógicos, no implica que sea distinta a la de sus propiedades dichas. De ahí que los objetos si puedan ser identificados - contra lo que cree Margáin-, en el uso de las oraciones que contienen nombres simples, como lo ha mostrado detenidamente un inteligente 
artículo de H. Ishiguru ("Use and Reference of Names", en Studies in the Philosophy of Wittgenstein, ed. P. Winch, Routledge and Kegan Paul, Londres, 1969, pp. 20-50).

Margáin piensa que el objeto queda agotado al predicar de él sus propiedades: "decir lo que es un objeto es usar las oraciones en las que ese objeto es el sujeto lógico y se predica de él un sustantival" (Art. cit., p. 111). Probablemente para el autor del Tractatus el uso de esas oraciones tendría dos funciones: indicar cómo es el objeto (al predicar algo de él) y mostrar que el objeto es (al referirse a él). El objeto es justamente el término de referencia de ese sujeto lógico $x$ del que se predica un "sustantival". De ahí que el objeto esté supuesto en el uso de toda oración con sentido, como su término de referencia, aunque no pueda mostrarse en ningún acto lingüístico distinto del que predique algo de él.

Las objeciones de Margáin se refieren a una doctrina que pretendiera que el objeto existe aparte de sus propiedades y que puede señalarse en un acto distinto al de la oración predicativa. Esa no es la doctrina del Tractatus.

La noción de "objeto" es oscura y probablemente errónea. Pero es difícil decidir sobre ella sin considerar los problemas que trata de resolver y sin analizar la concepción del lenguaje de que forma parte. Muchas páginas han dedicado los comentaristas a dirimir esos puntos. Sutilezas filosóficas, sin duda. La vía de Margáin tiene la ventaja de ser más decidida. ¿Para qué tantos análisis si una brillante metáfora -las moscas en el papel- demuestra la falsedad de la doctrina?

3. La doctrina sobre el "sentido de la vida", en Wittgen. stein, es también oscura. Basado, sobre todo, en los Notebooks, yo traté de aclararla: el sentido de la vida no tiene que buscarse fuera de ella, fuera, por lo tanto, de la totalidad de hechos que la componen; se comprende en el momento en que deja de buscarse en un hecho particular y no en el "hecho" mismo de vivirla. De ahí que el sentido de la vida consista en vivirla con plenitud y no en realizar un acto concreto o en 
perseguir un objetivo particular. En esa doctrina creí ver una afirmación filosófica del valor de todo lo vivido: el sentido de la vida es ella misma ... y ella no es nada fuera de la totalidad de los acontecimientos que la componen.

Margáin, sin embargo, fue más perspicaz. Se percató de que esa doctrina es, en el fondo, una "invitación a la muerte"; se dio cuenta de que, en verdad, predica "la pasividad total" y la "indiferencia" a todo acontecimiento vivido. Confieso que no alcanzo a seguirlo. La afirmación de que ningún acontecimiento de la vida es el sentido de ésta, no parece implicar una actitud de "indiferencia"; por el contrario, cualquier acontecimiento vivido adquiriría pleno valor en el momento en que no preguntara por otro acontecimiento que le diera sentido. Pero Margáin percibe lo contrario, lo que me hace dudar de si mi lectura fue la correcta. Tendré, pues, que decirlo con franqueza: aunque Margáin no demuestre cómo se deriva esa "invitación a la muerte" de la doctrina de Wittgenstein, si ésa es efectivamente la visión del mundo que nos propone el autor del Tractatus, comparto su indignación. ¡Andar con visiones místicas sobre la vida a estas alturas, cuando la psicología y la sociología -como bien dice Margáin- explican tan claramente la ética y dan cuenta del sentido de la vida! ¡Faltaba más!

Margáin, después de revelar las implicaciones místico-oscurantistas de la visión del mundo de Wittgenstein, tiene el mérito de oponerle sus propias creencias, racionales y científicas, como debe ser. "En resumen, dice, a la idea de Villoro [de Wittgenstein] de que lo ético es indecible, yo opongo la creencia de que es un fenómeno explicable por la psicología y la sociología; a su idea de que ...., opongo la creencia de que ..." y asi sucesivamente (Art. cit., p. 113). Bien está que un filósofo tenga el denuedo de exponer sus propias convicciones. Así, la refutación de la ética de Wittgenstein se muestra en todo su alcance: consiste en oponerle otras creencias, las que Margáin sustenta. Y éstas son tan claras y evidentes que ni siquiera tiene que hacer un esfuerzo 
por demostrar su validez: entre las oscuras doctrinas de Wittgenstein y las opiniones racionales de Margáin, cualquier individuo de sano sentido común optará por las segundas.

4. El Tractatus acepta la distinción entre lo que puede ser dicho en un lenguaje conforme a reglas lógicas (que coincide con lo pensable) y lo que no puede ser dicho en ese lenguaje; hay otra esfera, por lo tanto, que abarcaría el sentimiento y la "voluntad", diferente a lo pensable. A Margáin le parece falsa esta distinción, porque convierte el sentimiento y la voluntad en "arracionales". Oportunamente nos recuerda que "pensamiento, sentimiento y voluntad son tres funciones entrelazadas de la psicología humana" (Art. cit., p. 114). Frente a las especulaciones noseológicas, siempre es útil ese recurso a una sana psicología. En este punto, coincido con Margáin. Sólo cabrían algunas aclaraciones para resaltarlo.

La distinción de Wittgenstein no es psicológica. No se refiere a distintas "facultades del alma" o a algo por el estilo. Es una distinción noseológica entre el conjunto de hechos descritos en un lenguaje "figurativo", como el que presenta el Tractatus, y lo que es intuido, sentido, pero no es figurable en ese lenguaje. La distinción hereda de Kant y, más inmediatamente, reproduce la de Schopenhauer entre "representación" y "voluntad". Supone, sin duda, que hay una manera no proposicional de captar una realidad. Sentimiento y voluntad son pues "arracionales" en cuanto, por definición, se oponen a la esfera de lo "representable".

Rechazar en bloque y sin matices esa distinción - como lo hace Margáin- compromete a las siguientes tesis: a) El lenguaje figurativo - el que describe el Tractatus $\mathbf{u}$ otro semejante - es capaz de expresarlo todo; o sea, todo es pensable. b) Todo conocimiento se reduce a un saber proposicional; no hay ninguna manera de captar algo distinto a ese saber. Así se elimina no sólo la distinción Schopenhauer-Wittgenstein, sino también, cualquier otra que aceptara una forma de conocimiento distinta al "conocimiento por descripción". c) 
Todo lo intuido, sentido y querido puede ser descrito en forma exhaustiva por un lenguaje científico.

Margáin no ignora, sin duda, que con su rechazo tajante de la distinción se compromete a esas tesis. En efecto, no se limita a recordarnos la unidad de las facultades anímicas (por lo que Wittgenstein y yo lo felicitaríamos), sino también sostiene que todo acto psíquico es explicable por razones y reducible a conceptos científicos, concepción que atribuye a Freud (Art. cit., p. 114). Más aún, le parece $\longrightarrow$ si lo entiendo bien - que todo puede ser descrito por el lenguaje. Una tesis tan radical merece una exposición sistemática. Estoy seguro de que Margáin tiene amplios argumentos que la fundamenten. El hecho de que no dé ninguno en el escrito

- que comento me hace suponer que los reserva para algún trabajo posterior en el que por fin quede revelada la naturaleza racional de todos los sentimientos y reducida a lenguaje científico toda expresión volitiva o emotiva. Esperamos con interés su aparición.

5. Wittgenstein distingue entre hecho y valor. Sostiene que el segundo no puede ser descrito en enunciados de hechos. A Margáin le parece tan absurda esa postura que la echa abajo de un plumazo. Dos frases bastan. "Entonces - escribe¿No es un hecho que Villoro desaprobó la guerra de Vietnam? ¿Podemos describir completamente a Villoro y omitir éste y los demás datos acerca de lo que aprueba y desaprueba, de lo que odia o quiere, de lo que le gusta o le disgusta?" (Art. cit., p. 114). Con esto queda refutada la doctrina de Wittgenstein.

Aquí tenemos que reconocer que Margáin, contra su costumbre, fue por lo menos apresurado. La desaprobación de la guerra de Vietnam por Villoro incluye un conjunto de hechos psíquicos, tal vez sociales: creencias, actitudes, comportamientos, acciones; entre ellos, están las valoraciones sub. jetivas del propio Villoro. Pero ninguno de esos hechos incluye, como una nota propia describible en ellos, que sean valiosos. Esos hechos, que Villoro y Margáin pueden consi- 
derar valiosos, Nixon y Thieu los considerarían no-valiosos. El becho de que puedan describirse los actos de valoración no implica que pueda igualmente describirse el valor de esos actos.

Margáin sabe, por otra parte - aunque hábilmente finja ignorarlo- que la distinción de Wittgenstein no es tan ingenua. Tiene su historia. La más inmediata está en Moore. Wittgenstein recoge sus argumentos y su invitación a no caer en la "falacia naturalista". Sostener la tesis contraria (la reducción del valor a hechos) compromete a aceptar dicha "falacia" y a contestar las razones en su contra. La tarea no es sencilla. Las frases de Margáin antes citadas difícilmente pueden reemplazarla.

6. Por fin, a Margáin le parece inaceptable la noción de analogía que propuse en mi artículo, como hipótesis para explicar cómo algunos "sinsentidos" del Tractatus podrían ser "elucidativos". Creo que no le faltaría razón en considerar insuficiente mi explicación, aunque no se ocurre otra que aclare mejor ese problema. Trataré de precisarla brevemente.

La analogía se establecería entre: $(a)$ lo referido por una oración vaga del lenguaje ordinario, y $(b)$ lo captado por sentimientos e intuiciones que despiertan la comprensión de esa oración. Ninguno de esos dos términos es "ininteligible", como escribe Margáin. (a) es una situación objetiva vagamente descrita por el lenguaje ordinario, $(b)$ es algo no "figurable", pero experimentado por el sujeto en su mundo; para suscitar la experiencia de $(b)$ es menester comprender la oración que se refiere a $(a)$ y experimentar los sentimientos asociados con esa comprensión. Esta operación rebasa efectivamente el uso descriptivo del lenguaje científico, por ello pensaba que correspondería a otro uso, distinto al "decir" pero también al "mostrar". Sin embargo, nada tiene de extraordinaria; no difiere sustancialmente de la que es familiar a toda expresión poética. Las oraciones del Tractatus que se refieren a lo "indecible" tendrian, así, una función seme. jante a metáforas o alegorías poéticas. 
Ante una doctrina compleja y oscura, como la del Tractatus, caben dos vías de crítica. La primera consiste en tratar, antes que nada, de comprenderla, analizando cuidadosamente los problemas que intenta solucionar y las razones en que se funda; interpretarla, luego, de la manera más favorable posible, para no hacerle injusticia. Sólo después de esa doble operación, la crítica que la rechace será filosóficamente relevante. Pero el empeño de Margáin es otro. No le interesa comprender los errores ajenos sino desenmascararlos, no le importa analizar los argumentos en que pretenden basarse, sino señalar' su falsedad, para que a nadie induzcan a engaño. Para ello tiene que emprender otra vía más directa: bastará con ridiculizar la doctrina engañosa, simplificarla lo más posible y oponerle sentenciosamente sus opiniones verdaderas. Tenemos que reconocer la valentía intelectual de semejante empresa. Pues no es poca la de denunciar el error ajeno aún a costas de convertir su propia crítica en una trivialidad filosófica. 